\title{
Societal trends, mobility behaviour and sustainable transport in Europe and North America
}

\author{
Georg Rudinger*, Kieran Donaghy** and Stefan Poppelreuter*** \\ * Center for Evaluation and Methods \\ Bonn \\ Germany \\ e-mail: rudinger@uni-bonn.de \\ ** Department of Urban and Regional Planning \\ University of Illinois at Urbana-Champaign \\ Champaign \\ USA \\ *** Impuls GmbH, c/o Psychological Institute \\ University of Bonn \\ Bonn \\ Germany
}

EJTIR, 6, no. 1 (2006), pp. 61-76

This contribution describes the work of Focus Group three of the European Union network Sustainable Transport in Europe and Links and Liaisons to America (STELLA). It examines especially social and behavioural aspects of sustainable transport from a transatlantic perspective. Significant societal trends (e.g. the ageing of societies) are surveyed and their implications for mobility behaviour are drawn. The sustainability of this behaviour is considered along with constraints and drivers of this behaviour in Europe and North America. The contribution takes up relevant policy issues and concludes with a discussion of a transatlantic research agenda on social and behavioural aspects of sustainable transport.

Keywords: Mobility, Traffic and transport, societal trends and mobility, European-American comparative research

\section{Introduction: The STELLA network and its Focus Groups}

The sustainability of existing and emerging patterns of mobility behaviour in Europe and North America is questionable and is a subject of grave concern for transportation researchers, practitioners, and public authorities on both sides of the Atlantic. Many of these concerned individuals have been participating in the three year (2002-2005) STELLA Thematic Network project. STELLA is an acronym for Sustainable Transport in Europe and Links and Liaisons with America. The STELLA project is part of the European Commission's $5^{\text {th }}$ Framework Programme for Research and Development and is centred on common issues in Transatlantic transport research. STELLA aims to generate value added 
from knowledge exchange and to support a common research approach from both sides of the Atlantic, which will not only be to the benefit of the research community, but also of interest to policymaking bodies and industrial organisations. North Americans participated in the project through the STAR network (Sustainable Transportation Analysis and Research), which is supported by the US National Science Foundation, and Transport Canada.

The STELLA network has been addressing five major focus areas which have been identified as critical fields of interest for a transatlantic thematic network in the transportation field through dedicated focus groups. The STELLA thematic network has prompted an intense debate in both Europe and North America on the future perspectives of transport research and the foundations of policy analysis in this field (including the question on the formulation of policy lessons). Focus group members hail from the academy, industry, and government. Focus Groups 1 and 2 address the themes of Globalization, E-Economy, and Trade; and ICT, Innovation, and the Transport System. Focus Groups 4 and 5 address the themes of Environment, Safety, Health, Land Use, and Congestion; and Institutions, Regulations, and Markets in Transportation.

Focus Group 3 has been examining the dynamics between Society, Behaviour, and Private/Public Transport. Focus Group 3 has met three times, in Bonn in April 2002, in Arlington, Virginia in January of 2003, and in Lisbon in May, 2004. The principal objectives of these meetings have been to explore the interrelationship between social change and transport in the different spatial organisations and cultural contexts of Europe and North America, to identify commonalities and contrasts in forces determining spatial mobility in Transatlantic societies, to mobilise high quality research, and prepare central findings on the relationships between society, behaviour, and private/public transport for dissemination to a wider international audience.

\section{Societal Trends and implications for mobility behaviour}

Social change affects transport and is affected by transport. In close interaction with social values and individual attitudes, mobility and transport patterns are linked in complex ways with significant social trends, such as the adoption of suburban life-styles, the ageing of populations, the decline of the nuclear family, etc. It is increasingly evident that the corresponding (modern) lifestyles in affluent societies, and the mobility behaviours associated with such life styles, are not consistent with protection of environmental quality, efficient use of human, natural, and financial resources, and promotion of social cohesion and just distributions of opportunities and costs of using transport systems. Arguably, whether or not specific societal trends or combinations of trends are sustainable may depend in large part upon whether or not changes in individual behaviours can be brought about through policies that affect drivers and constraints upon relevant types of action.

This paper examines social and behavioural aspects of sustainable transport from a transatlantic perspective. In so doing, it draws heavily on papers that have been contributed to the above mentioned meetings of STELLA Focus Group 3 (Society, Behaviour, and Public/Private Transport) published in Donaghy, Poppelreuter and Rudinger (2005).

In the $20^{\text {th }}$ and $21^{\text {st }}$ centuries, both Europe and North America have witnessed urban settlement patterns of outward growth and lower densities and increased demands for personal transportation. As locations of residential, work, and leisure activities have become increasingly separated spatially, mobility has increased and come to be valued more. Social 
networks have become more far flung and there are perhaps fewer overlapping uses in the same place. Industrial production and distribution has also become more transit intensive as the relative cost of transport in production has steadily decreased. We consider first the broad sweep of these changes and then specific details of the specific cases of the United States, countries of the European Union, and Central and Eastern Europe countries.

As Axhausen (2005) has observed, the key societal development of the last 100 years has been the translation of accumulated differences between productivity and population growth into mass consumption. The key sectors in this process have been housing and transportation. In the period of reference, most populations of the OECD countries have achieved almost complete motorization. Increased access to transport has been translated into use and associated speed gains translated into longer distances travelled. The literature suggests consumers have a constant "travel budget", or tend to spend the same amount of time travelling regardless of speed of travel, and the pattern is discernible in all OECD countries (Axhausen, 2005).

Increases in housing consumption, distances travelled, and telephone contact have led to a rearrangement of expenditures from increasing household budgets. While expenditure shares of food have dropped considerably, expenditure shares of leisure, education, travel, and communication have all nearly doubled since the early 1900s. While the larger shares of expenditures on leisure and education reflect longer life expectancy, more years spent in education, shorter work weeks, and longer retirements, the adoption of the automobile is the primary reason for the increase in the expenditure shares of travel and communication.

The motorized, connected, and spatially dispersed populations of today have different patterns of work and socialization than the populations of 50 years ago. Daily life revolves around friends, family, work, school, and shopping. The distribution over space of these commitments and opportunities shapes the activity space of a person in his or her everyday environment. The size of this activity space determines a person's consumption of transport services. Increasing distances between the poles of a person's activity space have far reaching and permanent effects, which cannot be reversed quickly, given long-term investments made in work, family, and friendship. Society has increasingly become based on spatially dispersed networks, which are weakly overlapping. The breakdown of walking environments and the weakening of closed social milieus have been contributing factors. In view of these trends, one may assume that not only will the members of social networks be spatially dispersed, but social networks will be less coherent - i.e., fewer people who are spatially proximate will share multiple affiliations.

Within the last 25 years personal miles travelled in the United States (U.S.) has increased by $80 \%$, a rate which is almost 3 times that of population growth over the same period. While there has been increased demand for automobile use over the last few decades, the same cannot be said for bus and transit use. The downward trend in transit ridership, which began in the 1950s, can be explained in part by the patterns of metropolitan form that have evolved (Schintler, 2005). In many metropolitan areas, the suburbanization process has given rise to polycentric patterns of development and the emergence of edge cities, urban sprawl, and areas of low-density development. These patterns are not conducive to transit use, neither bus nor rail, as they lack the density required to support efficient operation. The development of information and communications technologies and their use in control of production and supply-chain logistics have contributed to a functional division of labour in space or vertical and horizontal fragmentation of industrial production, the development of just-in-time and other approaches to production that are generally more transport-intensive. In the United 
States the logistics revolution has contributed significantly to the volume of freight shipments. Commodity-flow data for 1993 and 1997 indicate a 3\% increase in the value of shipments but a $27 \%$ increase in tonnage and a $12 \%$ increase in ton-miles (Munroe and Hewings, 1999). Most trade in both North America and Europe is now intra-industrial in nature and interregional trade is increasing because of increased specialization of establishments and increased complexity of production processes. Economies of scope, as well as scale, are being exploited at the multi-plant level (Jones and Kierzkowski, 2001).

In the countries of the European Union (prior to May 2004) there has also been a spectacular increase in automobile use. Presently $80 \%$ of all passenger journeys are made by car, $8 \%$ by bus, $6 \%$ by rail, and $5 \%$ by air (European Commission, 2003). Air transport has grown rapidly, with passenger traffic rising at an average annual rate of more than $7 \%$ over the last 20 years. Rail transport, however, has been in decline as market share for passenger traffic has declined from $10 \%$ to $6 \%$, and from $21 \%$ to $8 \%$ for freight. This decline reflects some problems of rail: railways are slower and less reliable than road transport, national railways operate according to different standards and have not done enough to integrate with each other. While water transport is viewed as the poor relation among different forms of transport, $41 \%$ of goods transported within the EU travel by ship over short-sea routes.

Suchorzewski (2005) reports that, in the Central and Eastern European Countries (CEEC), since 1990 passenger trips made by car have increased by 5 to $7 \%$ per year. The number of passengers served by railways has dropped by about $5.7 \%$ per year, as has use of intercity bus transport. In some CEEC the state has completely withdrawn from its role as owner and financier of urban transport, while still preserving part of control over urban finances. In some countries, such as Poland, emphasis has been placed on mobility management in an effort to decouple economic growth from transport intensity.

Although walking and cycling are the most economically, socially, and environmentally sustainable forms of human mobility, they are not adequately catered for in policies or practice in either North America or Europe and are in decline (Gaffron, 2005). We note that in the European Union there is a significant unfulfilled potential for them since $50 \%$ of all trips are shorter than 3 kilometres, a distance which can be walked in 25 minutes or cycled in 10. Yet statistics show that the modal share of walking and cycling in Europe is declining (DGTREN, 2002). Spatial spread in social networks, motorization of private transport, and policies encouraging more of the same have together contributed further to a decline in walking and cycling.

\subsection{Mobility needs of the socially excluded, elderly, and female transport system users}

The nature and pattern of social exclusion is quite different between the U.S. and European countries, as well as among European countries. First, redistribution policies are more limited in the U.S. Second, social exclusion in the U.S. is heavily concentrated in the inner city and rural areas, mainly due to the intersection of poverty and exclusion with race and ethnicity and related discriminatory practices in the U.S. housing market (Kaplan and Halloway, 1998). Third, the dominance of the private vehicle in U.S. urban transport makes automobile mobility essential everywhere, with the possible exception of the centers of the largest cities. Low-income households are much less likely to own an automobile, and, when they do, it tends to be much older. Low-income individuals tend to walk and the ride the bus more than higher-income individuals. 
Certain groups are disproportionately at risk of social exclusion and people are most vulnerable at particular stages of the life cycle. The primary dimension of social exclusion is poverty. Of those suffering relative poverty, six groups are most at risk: children, young people, older women, the unemployed, single parents and large families.

Because the U.S. poverty definition is based on fundamental needs (e.g., food consumption requirements), adjusted for household size and composition, the poverty rate defined is much lower than in the EU. The European Council's joint report on social exclusion, published in December 2001, recognizes the need for a broader approach assessing exclusion, which not only emphasizes low-income but also access to equally relevant aspects such as jobs, education, housing, healthcare, the degree of satisfaction of basic needs and the ability to participate fully in society (Council of the European Union, 2001).

Pickup and Giuliano (2005) have identified transport related factors that compound the primary risks of social exclusion in both Europe and the U.S. Several examples are as follows. Travel patterns become tied to the monthly cycle of social benefit payments, contributing to access and mobility patterns of the unemployed. Difficulties accessing facilities limit the ability to maintain social contact of low-income elderly people who are reliant on public transport. The high cost of transport for low-wage workers restricts their social activity space, reinforces a local lifestyle, and increases the likelihood of further social exclusion. Children and teenagers from transport disadvantaged families suffer from their limited ability to travel beyond their "disadvantaged" area.

The populations of both continents have been ageing as the proportion of the population at 65 years of age or older is at its historical high. People are living longer and having fewer children, although the latter phenomenon is more pronounced in Europe (N.N., 2002). Of those living longer, more are women. With the aging and feminization of the population has also come a shrinking of the middle class and an increased spatial concentration of lowincome members of society (see, e.g., Krugman, 2003).

In both Europe and North America women's travel patterns are converging with those of men at the aggregate level, in the sense of increased automobile use and less use of transit, walking and cycling. Where women's travel patterns differ from those of men is at the micro level. Whereas trips of men tend to be more single-purpose, women trip-chain more (Schintler, 2005). Kwan's (2003) research concerning personal spatial-time prisms also reveals that women tend to be more constrained in their mobility by their obligations as primary care providers. Such obligations also contribute to women having more complicated and difficult commutes than men. As more women drive, their accident rates are expected to increase proportionately, but injuries are expected to increase more than proportionately. This is so not because women are less safe drivers than men, but because they are more vulnerable physically (Rosenbloom and Hakamin-Blomqvist, 2004). Even as these generalizations can be made, it is important to note that women's travel needs and problems are not homogeneous. Elderly, female, and socially excluded (principally, low-income) users of public and private transport have different mobility needs which are met more or less well by existing systems.

\subsection{Ageing and its implications for mobility behaviour}

Especially aspects concerning the ageing of societies and elderly persons have been taken into account in Focus Group 3 (see also European Conference of Ministers of Transport, 2000). One of the most significant societal trends is the ageing of societies. An increasingly 
larger proportion of the population is reaching old age. In nearly all countries of the western world the elderly already make up over $12 \%$ of the total population, and this percentage is projected to increase substantially year by year. An increasing number of these individuals are licensed to drive, and they drive more than their age cohorts a decade ago. In view of the constantly increasing number of old and very old persons in our societies it is no surprise that their mobility behaviour has become an issue of public and scientific interest (Schaie and Mollenkopf, 2005). On the one hand, mobility (the ability to move about) and traffic (the transportation of people, goods, and news) have become an even more important precondition of ensuring the ability to lead one's everyday life, keep up social relations, take part in every kind of activity outside one's own four walls, and seek out places subjectively significant or objectively central to provide for daily material needs and health care. On the other, mobility is increasingly jeopardised as a person ages (Waldorf and Pitfield, 2005). The profound changes in the demographic structure due to the growth of ageing populations in developed countries, especially in the European Union countries and the United States, will clearly require a profound reorganisation of society, both in public services and in private supply. The elderly users will be qualitatively different, as they will work longer, be more alone, and have a higher level of education. The majority of the elderly would probably require greater mobility than at present, regarding the need to work, travel and have interpersonal contacts (Schaie and Mollenkopf, 2005). However, it can also be assumed that the current 'ageing of ageing' will increase the number of persons with reduced mobility performance or with cognitive and sensory disorders (e.g. sight, hearing), who today are often only potential users or excluded ones? Therefore emphasis should be placed on the expected increase in the number of elderly persons with mobility impairment and the transportation challenges associated with this change. In order to keep older persons mobile and allow them to be independent it is important to know their mobility patterns, attitudes to transport and different needs, with special attention given to elderly persons with mobility impairment.

For the elderly, mobility is a quality of life issue. It is essential for maintaining attributes of personal choice and independence, familiar habits, and lifestyle. Mobile elderly are able to reduce personal isolation, participate in recreational activities, obtain goods and services, maintain access to financial and personal consultants, remain active in a religious or spiritual community, and maintain intellectual stimulation. Although aging is accompanied by waning strength, the needs of the elderly and disabled are different.

While the populations of all European and North American countries are aging, the aging process differs across countries. Simultaneously, there is a feminization process (or increase in percentage of women in the population) that varies across countries. As women age they tend to drive less or cease driving altogether more so than men. The growing difference between the numbers of elderly who survive and cease to drive (or do not drive) and those who survive and continue to drive indicates that there will be a growing demand for trips that are not auto-dependent. While the difference is greater for women than for men, the number of elderly men and women needing public transportation services will be increasing. On the basis of multiple-risk survival models, Pitfield and Waldorf (2005) project that this difference will become particularly critical in the U.S. around the year 2018. This potential development has a number of implications.

Different perspectives can be chosen to analyse the relationships between influencing factors and elderly people's outdoor mobility and traffic behaviour in general. One focuses on 'causal' factors. For example, what socio-demographic and psychological characteristics are associated with the driving behaviour of the elderly? This perspective is chosen frequently in 
traffic research studies. Another perspective might be called a segment-specific approach: Can the elderly as a group be subdivided into homogeneous subgroups? For example, are there variables that characterise those elderly persons who have a positive attitude toward public transport?

It is important to bear this second perspective in mind, since 'the elderly'- and particularly the 'very old'-are a heterogeneous group (Schaie and Mollenkopf, 2005). This helps us to identify and understand their different mobility needs, their diverse driving behaviour, and the variety of their compensatory strategies (Rudinger and Jansen, 2003). This perspective allows to determine the size of the different homogeneous subgroups of the elderly and to identify the characteristics of these subgroups as a basis for improving traffic safety and options for outdoor mobility. Based on life-style differences (e.g. stimulation-seeking, intellectually curious, indifferent, passive, and negativistic) it is possible to isolate different types of mobility patterns of the elderly (Rudinger, 2002). Typological approaches confirm the existence of groups of elderly deserving special attention with regard to intervention, rehabilitation and prevention (Willis, 2003).

A comprehensive notion of mobility should take into account the degree of mobility realised, the range of activities engaged in, the variety of transportation modes available to users, and satisfaction with mobility. As women age, they tend to drive less or cease driving altogether more so than men. The growing difference between the numbers of elderly who survive and cease to drive (or do not drive), and those who survive and continue to drive indicates that there will be a growing demand for trips that are not automobile dependent (Tacken, 2004). While the difference is greater for women than for men, the number of elderly men and women needing public transportation services will be increasing (Pitfield and Waldorf, 2005). This potential development has a number of implications. In addition to a need for greater provision of public transportation, especially if older persons should be convinced to quit driving, traffic management will need to be adapted to the changing driving population (Hakamies-Blomqvist, 1993; Rosenbloom and Stahl, 2002).

In addition to a need for greater provision of public transportation, especially if older people should be convinced to quit driving, traffic management will need to be adapted to the changing driving population. Road markings and street signs will need to be made more visible, intersections simplified, HOV lanes increased and infrastructure and vehicles redesigned. The relocation of residences and facilities for retirement communities will also need to be better planned. Public transportation will need to be adopted to the needs of elderly users and information technology used more widely. And if "aging in place" is to become a real option for more elderly men and women, more demand-responsive transit will need to be provided. Nevertheless, the car will be widely used by the older population, and car industries will therefore have to design cars that meet the real needs of the elderly and their gradually declining functions. In this direction the new technologies (ICT, telematics) might give considerable support.

\subsection{Society, behaviour and sustainable transport}

Against this background of information on trends in settlement patterns, mobility behavior, and the habits and needs of specific user groups (e.g. the elderly), we consider meanings of sustainable transport. Virtually all notions of sustainability have to do not only with the persistence of systems but also the conveying of a healthy state of a system from one generation to the next. Since the Brundtland Report (World Commission on Environment and 
Development, 1987) it has been recognized that sustainability must be viewed in a number of dimensions. Minimally these would include environmental, economic, and social (Heal, 1993). But there is also an argument for the inclusion of the cultural dimension. The question of sustainability vis a vis transport systems concerns not only what level of personal mobility and flexibility is environmentally and economically sustainable (for living and future generations) but also what differences in transport service availability and effective access can be consistent with social cohesion. Lakshmanan (2001) has identified five properties of a sustainable transportation system: i) urban forms must be planning driven and transitfriendly; ii) transit mode choices should be market driven; iii) infrastructural investments should be efficiency driven; iv) financing must be innovative; and iv) the system must be flexible enough so that it can be reinvented. With this dimension in mind we might also ask what level of environmental quality is socially sustainable.

If our aim is to arrive at settlement patterns, transport systems and patterns of usage that are sustainable, we need to understand better the constraints upon and drivers of mobility behaviour. In a recent survey of transportation and land-use linkages, Boarnet and Medda (2003) have identified two types of linkage. In the first, transportation infrastructure influences land use, and in the second, urban form affects travel behaviour. Empirical studies reveal that in the former, the speed of adjustment of land use to transportation infrastructure may be measured in decades, whereas in the latter, the speed of adjustment of behaviour to urban form may be instantaneous. Among the crucial findings made are that mixed land uses are associated with a reduction in trips, the growth of road networks coincides with population growth, and the influence of transportation infrastructure on development is large. In an elaboration of analytical models (based on fairly strong assumptions) Medda and Boarnet (2005) demonstrate how transport costs can influence the length and width of a central business district (CBD), how the area allocated to transport can influence the shape of $\mathrm{CBD}$, and how urban form is affected by traffic flows of different transportation modes. The models they consider may be used to analyze how the amount of area dedicated to different transportation modes will affect urban form.

In a recent survey of literature on behavioural aspects of road users, Richardson and Stern (2003) have examined formal and empirical characterizations of travel behaviour. They trace a progression of behavioural modelling approaches from random-utility to rule-based paradigms and activity-based and process-oriented frameworks. In the latter type of model, motives and needs drive decisions made under constraints, which lead to response behaviour (in the form of driving behaviour and travel demand) over space and time. In comparative studies of travel patterns in Europe and North America, differences in travel and mobility can be traced to constraints that may take the form of income, network densities, transport technologies, and social trends. Since models are conceptual in nature, determining their usefulness in understanding behavioural aspects of transport behavior requires empirical testing. Appropriate data, however, are often difficult to obtain and hence much about travel behaviour remains unaccounted for empirically. Richardson and Stern propose the use of decision-field theory, in which the process of deliberation is explicitly considered.

In considering questions that empirical studies have framed, Richardson and Stern observe that there are issues concerning long-term versus short-term decision making, socioeconomic determinants, and cultural differences. The residential decisions of multiple-occupation households would appear to be particularly important to investigate. Richardson and Stern observe that considerable research has been conducted on factors affecting the time of day of travel, route choice, optimal commuting patterns, modal choice, vehicle choice, and urban 
form. It may be the case, however, that multiple decision processes are involved in the determination of travel behaviour and that we are unlikely to get very far in policy making without better theories of what drives travel behaviour in the context of multiple decisions. From the perspective of empirical research, it is easier to test specific hypotheses about travel behaviour than to operationalize aggregate models in which compound hypotheses are empirically confronted. Richardson and Stern also note that even if improvements in theoretical explanations of travel behaviour can be achieved, it remains to translate them into effective policy prescriptions. And it is questionable whether a more universal model of transportation behaviour would explain observed differences when people in different situations often use different decision-making heuristics.

Current transport system configurations and their use have come about through a combination of technological innovations, private initiatives, and public policies. There is a certain social inertia built into transport systems that is difficult to change. And even as we may come to understand better the mobility needs and behaviours of particular user groups or individuals, understanding individual behaviour may not help us to understand system effects that can be counter-intuitive (Vickerman, 2001.) .

\section{Policy considerations}

Policies are commonly viewed as rules for responding to recurring conditions or situations. As such they can be both explicit and implicit about what they permit or forbid. Policies are often shaped in response to unmet needs. And policies may be used to develop information from which to learn about system responses (Intergovernmental Panel on Climate Change, 2001). Much we have discussed above has to do with the special needs of particular transport system users that are now unmet. Those needs are themselves conditioned by infrastructure provisions and long-term commitments.

A common distinction made between policies whose intent is to influence or modify behaviour is between those that are market-incentive based and those that are command-andcontrol in nature. In the area of transport policy, Europeans are more comfortable with both command-and-control and price measures (road pricing, fuel taxes) to recover costs of providing public transit and achieve reductions in congestion and emissions than are North Americans.

Policies are generally evaluated in terms of efficiency and equity. There are external costs to transportation behaviour not paid for by transport system users. These include economic, regulatory, and infrastructural costs. Any proper assessment of the equity of impacts must take into account how these costs (and the benefits derived from transportation systems) are distributed both intra- and inter-generationally and how transport facilities and services are distributed spatially. Economic theory suggests how optimal tax and investment rules should be constructed: the efficiency and equity of any policy reforms should be assessed in terms of whether or not the reforms are revenue neutral. To design better schemes for redistributing costs and benefits of transport systems, instruments other than taxes should be considered, locational analyses of the effects of transport policies should be made, and more detailed analyses of impacts on difference income groups should be conducted. Bae and Mayeres (2003) observe that equity tends to be evaluated mostly in terms of income. Typically, the lower is a transport system user's income the greater is the percentage of his or her income expended on transportation. Since adopting strict efficiency rules for pricing transportation 
will likely impact the poor adversely, a pro-equity policy may involve a second- or third-best approach in which there is a redistribution of revenues collected from externality-related cost fees. A pro-equity transportation policy must also focus on demand-side assistance. In spite of policies intended to increase transit use, metropolitan areas in the U.S. have experienced an increase in vehicle miles travelled without an increase in transits share. While technological developments in the automobile industry hold promise for improvements in energy efficiency and air quality, their costs and diffusion time render short-term equity impacts negligible. If pro-equity policies are desired by society, both command-and-control and market incentive measures might be used to good effect.

In designing policies that meet the needs of different user groups and are efficient and fair in their delivery, transportation policy researchers will have to learn to package policy recommendations with strategies of adaptation and work more closely with targeted stakeholder groups. In general policy must take into account that sustainable transport and mobility systems require the co-existence of several different mobility modes. Moreover concepts of mobility management must be fostered and tax policies should not unsuitably favour a singular mobility mode.

We need a policy that avoids discrimination and social exclusion (mobility as a 'basic right', e.g. access to mobility for everyone, reasonable tax policies), especially concerning the elderly. Social, urban and traffic planning should be coordinated on micro-, 'meso-' and macro-levels (e.g. implementation of advisory boards of elderly in local/city councils). The accessibility, safety and security of different mobility systems (from an objective and a subjective attitudinal perspective) should be improved. On a transport dimension a balance between modes and means of transport is necessary, so that those who give up the use of a private car have available alternatives of good quality, without any discrimination. On a social dimension it must be assured that citizens are provided with a mobility system adequate for their needs and that no exclusion through price, or any other criteria, will be imposed on the base of economic or financial grounds.

\section{A transatlantic research agenda}

The present political environments in Europe and North America are very different, but the aggregate pictures of transport system use by citizens are similar and are converging (Schintler, 2005; Suchorzewski, 2005). Whereas the European Union seeks to implement a pan-European policy whose particulars are being worked out at the national level, there is a less of a unified thrust in North American countries. And whereas European cities are more ready to implement aggressive command and control and market oriented policy measures, North American cities are more passive.

Bringing about planned behavioural changes that promote sustainable transport systems will require (at a minimum) deeper understanding of complex social phenomena, hence it will require research on the behavioural foundations of such phenomena. Conditions for applied comparative research in both Europe and North America regarding behavioural motives, innovative strategies and policy assessment in the transportation sector with a view to sustainable transport should be fostered and created. We identified a set of research questions that might be grouped loosely according to whether they are of a more fundamental or more applied (policy-oriented) nature and conclude with reflections on what is needed to encourage fruitful international comparisons and explore transition paths to sustainable transport. 
Research infrastructure and research policy issues are necessary to encourage international comparative studies and to facilitate international cooperation in the transatlantic study of social aspects of sustainable transport. Common surveys should be carried out in the United States and Europe and will provide useful comparative findings. For example, as the populations of Europe and the United States continue to age, transnational collaboration is essential to create environments that meets the needs of the elderly so that they can live their later years as active and valuable citizens of our communities (Marcellini and Allen, 2004). Particularly, the study on the communalities/differentiations of these effects in different spatial-economic and social contexts has been identified as necessary area of research. Crosscultural research is then envisaged in the design of a comparative analysis between Europe and North American. There is also a need for benchmark assessments of how well common models capture stylised facts of travel behaviour in Europe and North America. Hence different spatial levels - from theoretical, methodological and empirical viewpoints - might be analysed, by investigating concepts, data, and particularly the different speeds of ICT and transport dynamics and behavioural responses.

In this framework, there is a need to deepen, in both the European and North American contexts: (a) theoretical perspectives (such as the possible change of paradigms or modelling, e.g. in the sustainability concept, decay functions, behavioural models, forecast methods, and in general, in transport theory), (b) methodological issues (such as the exploration of new research methods, e.g. structural equations, multilevel models, self-organised criticality issues), (c) empirical evidence on the ongoing (un)sustainable transport-economic and social scenarios and (d) a strategy for inferring meaningful policy lessons in the context transport policy research. These ingredients appear to be a common focus, with a view to the related policy analysis and the future elaboration of a policy research agenda.

\subsection{Fundamental research questions}

A number of fundamental research questions are raised by the increasingly dispersed nature of social networks. Does the increased selectivity of social networks improve the quality of life? Will reduced local networking lead to more reliance on commercial or governmental services, especially in times of crisis? What are the implications for short-term travel behaviour of longer-term commitments to residential ownership, employment, automobile or seasonal travel pass ownership, and social network membership?

Reflections on societal trends in North America and Europe give rise to questions about the nature of attitudes toward sustainability and the nature of the relationship between attitudes and actual decisions. To what extent can attitudes toward and the valuation of mobility within highly mobile cultures be changed and how much individual mobility can be permitted in a sustainable transportation system? Related questions concern how lifestyles can be influenced and what the effect of established land use patterns on lifestyles and attitudes might be. An open question of historical importance concerns the extent to which Central and Eastern European countries might be able to avoid the negative consequences of the growth of mobility experienced by Western European and North American countries. In view of the inertia of established patterns of travel behaviour, it is important to inquire how effective in facilitating progress toward sustainability road pricing, teleworking and telecommuting programs, intelligent transportation systems, alternative transport arrangements, or innovative management schemes might be. 
Focusing on the needs of particular user groups, there is a clear need to establish a consistent definition of social exclusion (in its many forms) and its relationship with mobility needs as accommodated by transport systems. There is also a need to study how socially excluded people cope with restricted mobility and a need to compare U.S. and European cities vis a vis job access and employment. Regarding the latter, a relevant research question is whether the greater centrality and spatial concentration of European cities, together with their better public transport, lead to less disparity in job access and less "spatial mismatch" between locations of residence and employment than occurs in the U.S.? Or is there a European analogy to the "permanent underclass" of North American societies? What are the distributional implications of differences in the cost of owning and operating an automobile in Europe and in North America? Are the European elderly ageing in place or are they moving to less costly and more remote areas?

Thus improvements in the mobility situation of elderly must focus as much on transport policy and socio-political measures as on appropriate urban development planning. It is important to create flexible, user-centred options for mobility that offer a genuine alternative to both the private automobile and traditional local public transport services, and provide for neighbourhoods that also respond to the needs and wishes of an ageing population. For the elderly, whose life space contracts with advancing age because of their inability to overcome environmental obstacles, it is crucial that the areas near their homes have readily accessible stores, medical and care services, appropriate public transport and other facilities that will allow them to continue leading independent lives and being full members of society.

\subsection{Applied research questions}

Among the questions that arise concerning the linkage of research to policy formulations and applications for achieving sustainable transport systems are the following. To what extent do different user groups require special policy interventions and how should we weight tradeoffs between accommodating special needs and transportation system efficiency costs? How much do we need to know about behavioral drivers in order to design effective policies (to control, e.g., congestion and emissions)? What kinds of policy measures would best facilitate travel by both elderly and young? How can the findings of empirical research about transportation behavior be made available in formats useful to policy makers? How should income redistribution schemes be designed to promote greater equity among different transportation system user groups?

\subsection{Research infrastructure to encourage international comparison}

To facilitate international cooperation in the transatlantic study of social aspects of sustainable transport there is a need for the development and sharing of data sets. There is also a need for benchmark assessments of how well common models capture stylized facts of travel behavior in Europe and North America.

\subsection{Exploring transition paths to sustainable transport}

Five properties of a sustainable transport system were enumerated above. These properties do not indicate which particular system arrangements are in the feasible set of arrangements, but may help us to identify candidates for feasibility. Just how transportation researchers should go about exploring the feasible set in interactions with policy makers and stakeholders is 
itself a question to be researched. It seems reasonable, though, that researchers will need frameworks for conducting though experiments about making transitions to alternative steady states, frameworks which will integrate models of transportation, land use, industrial production and distribution. Clearly such integrated models must have temporal, spatial, and sectoral scales and scopes that permit adequate characterization of the problematic. They must, moreover, characterize faithfully processes of disequilibrium adjustment to be able to reproduce the development of historical problems and convey a realistic sense of time frames of these problems - resolution - i.e., they must capture lumpy changes in durable built environments and long-term commitments of transport systems users that such environments influence. Such modelling frameworks must enable researchers to distribute costs and benefits to different stakeholders, many of whom are not yet living, if they are to support political deliberations. Because our knowledge is limited, our foresight imperfect, and out habits persistent, such modelling frameworks need to incorporate explicit treatments of learning and behavioural change. And because system interventions in the form of policy decisions take time to implement and often induce unintended consequences, our models need to help us to think carefully about what and how certain types of decisions are conditioned by others.

Assuming significant headway can be made in research to support deliberations about sustainable transport policies, there remains other important work for researchers concerned about such policies. Vickerman (2001) urges transportation researchers to raise public awareness of systems relations by doing a better job of "connecting the dots" in public forums. He also urges researchers to work to persuade the public of the importance of and need for significant changes that many are reluctant to consider. Lakshmanan (2001) remarks upon the need to improve the quality and meaningfulness of interactions between researchers

and stakeholders and the need to study how to package strategies for sustainable transport for implementation at the local and regional levels. The position of transport and communication in society and economy raises many intriguing policy and research questions. Transport is at the crossroads of strong but antagonistic interests, which can be summarised under the following headings: continued economic growth, fair geographical accessibility, and favourable quality of life. These research and policy issues in the transportation sector are certainly not unique for the STELLA-STAR partners but are also abundantly existent in many other countries, regions and cities in our world.

\section{References}

Axhausen, K. (2005). Social networks and travel: Some Hypotheses. In: Donaghy, K, Poppelreuter, S. and Rudinger, G. (eds.) Social dimensions of sustainable transport: Transatlantic perspectives. London, Ashgate, pp. 90-108.

Bae, C. and Mayeres, I. (2003). Equity Considerations in Transportation Policies. paper presented at the second meeting of STELLA Focus Group 3, Arlington, Virginia, January.

Council of the European Union (2001). Draft Joint Report on Social Inclusion. DG Employment and social Affairs report 15223/01, Brussels. 
DGTREN (European Commission Directorate-General for Energy and Transport, in cooperation with Eurostat) (2002). European Union Energy and Transport in Figures 2001. http://europa.eu.int/comm/energy_transport/etif/list_of_tables.html/TRANSPORT.

Donaghy, K., Poppelreuter, S. and Rudinger, G. (eds.)(2005) Social dimensions of sustainable transport: Transatlantic perspectives. London, Ashgate.

European Conference of Ministers of Transport (2000). Transport and ageing of the population. Report of the $112^{\text {th }}$ Roundtable on Transport Economics, held in Paris on $19^{\text {th }}$ $20^{\text {th }}$ November, 1998. OECD, Paris

Gaffron, P. (2005). The implementation of walking and cycling policies. In: Donaghy, K., Poppelreuter, S. and Rudinger, G. (eds.) Social dimensions of sustainable transport: Transatlantic perspectives. London, Ashgate, pp. 195-208.

Hakamies-Blomqvist, L. (1993). Compensation in older drivers reflected in their fatal accidents. Accid Anal Prev, vol. 26, pp. 107-112.

Heal, G. (1993). Valuing the future: economic theory and sustainability. Columbia University Press, New York

Heal, G. (1993). Valuing the Future: Economic Theory and Sustainability. Columbia University Press, New York.

Intergovernmental Panel on Climate Change (2001). Climate Change 2001: Impacts, Adaptation, and Vulnerability: Summary for Policymakers. Online report.

Jones, R.W. and Kierzkowski, H. (2001). AA Framework for Fragmentation. In: Arndt, S.W. and Kierzkowski, H. (eds.) Fragmentation: New Production Patterns in the World Economy. Oxford University Press, New York.

Kaplan, D. and Holloway, G. (1998). Segregation in Cities. Resource Publications in Geography, Association of American Geographers, Washington, DC.

Krugman, P. (2003). A For Richer: How the Permissive Capitalism of the Boom Destroyed American Equality. The New York Times Magazine, October 20.

Kwan, M-P. (2003). A New Information Technologies, Human Behavior in Space-Time, and the Urban Economy. Paper presented at STELLA TRB Session 335, Washington, DC, January.

Lackshmanan, T.R. (2001). A Sustainable Transit with a Focus on Developing Countries. paper presented at workshop on European and North American Perspectives on Sustainable Transportation, University of Illinois at Urbana-Champaign, March 2001.

Marcellini, F. and Allen, S. (2004). Personal behaviour and sustainable transport: mobility problems and transportation needs of older people in Europe and the US. Presented at the $3^{\text {rd }}$ meeting of STELLA Focus Group 3, Lisbon, Portugal.

Medda, F. and Boarnett, M. G. (2005). An Analysis of the Effects of Urban Land Use on Transportation. In: Donaghy, K., Poppelreuter, S. and Rudinger, G. (eds.) Social dimensions of sustainable transport: Transatlantic perspectives. London, Ashgate, pp. 127-143. 
Munroe, D.K. and Hewings, G.J.D. (1999). The Role of Intra-industry Trade in Interregional Trade in the Midwest of the U.S. Discussion Paper 99-T-7, Regional Economics Applications Laboratory, University of Illinois, Urbana (www.uiuc.edu/unit/real).

N.N. (2002). Special Report: Demography and the West. The Economist, August 24, pp. 2022.

Pickup, L. and Giuliano, G. (2005). Transport and Social Exclusion in Europe and the USA. In: Donaghy, K., Poppelreuter, S. and Rudinger, G. (eds.) Social dimensions of sustainable transport: Transatlantic perspectives. London, Ashgate, pp. 48-49.

Pitfield, D. and Waldorf, B. (2003). Effects of Gender and Aging on Travel Behavior. Paper presented at the second meeting of STELLA Focus Group 3, Arlington, Virginia, January.

Rietveld, P. and Stough, R. (2002). Institutions, Regulations, and Sustainable Transport: A Cross-national Perspective. Paper presented at the STELLA Policies and Issues Forum, Brussels, April.

Rosenbloom, S. and Stahl, A. (2002). Automobility among the elderly: the convergence of environmental, safety, mobility and land use issues. Presented at the meeting of STELLA Focus Group 4 Meeting, Helsinki, Finland.

Rosenbloom, S. and Hakamin-Blomqvist, L. (2004). Women and Sustainable Transport. Paper presented at the third meeting STELLA Focus Group 3, Lisbon, May.

Rudinger, G. (2002). Mobility behavior of the elderly. In: Black, W.R. and Nijkamp, P. (eds.) Social change and sustainable transport. Indiana University Press, Bloomington, pp. 157164.

Rudinger, G. and Jansen, E. (2003). Self-initiated compensations: results and suggestions from the study AEMEÏS. In: Schaie, K.W., Wahl, H.W., Mollenkopf, H. and Oswald, F. (eds.) Ageing independently: living arrangements and mobility. Springer, Berlin Heidelberg, New York, pp. 220-233.

Schaie, K-W. and Mollenkopf, H. (2005). Mobility issues in the United States and Europe. In: Donaghy, K., Poppelreuter, S. and Rudinger, G. (eds.) Social dimensions of sustainable transport: Transatlantic perspectives. London, Ashgate, pp. 50-66.

Schintler, L (2005). Society, Behavior, and Private/Public Transport: Trends and Prospects in North America. In: Donaghy, K., Poppelreuter, S., Rudinger, G. (eds.) Social dimensions of sustainable transport: Transatlantic perspectives. London, Ashgate, pp. 29-37.

Stern, E. and Richardson, H. (2005). A New Research Agenda for Modelling Travel Choice and Behaviour. In: Donaghy. K., Poppelreuter, S. and Rudinger, G. (eds.) Social dimensions of $\quad$ sustainable transport: Transatlantic perspectives. London, Ashgate, pp. 144-163.

Suchorzewski, W. (2005). Society, Behavior, and Private/Public Transport: Trends and Prospects in Transition Economies of Central and Eastern Europe. In: Donaghy, K., Poppelreuter, S. and Rudinger, G. (eds.) Social dimensions of sustainable transport: Transatlantic perspectives. London, Ashgate, pp. 14-28.

Tacken, M. (2004). Trip making behaviour among elderly in time and space. In: Mollenkopf, H., Marcellini, F., Ruoppila, I. and Tacken, M. (eds.) Age and outdoor mobility. A European study. IOS, Amsterdam. 
The European Commission (2003). Europe at a Crossroads: The Need for Sustainable Transport. Brussels.

Vickerman, R. (2001). Transport Intensity and the Debate on Decoupling Transport Growth from Economic Growth. Paper presented at workshop on European and North American Perspectives on Sustainable Transportation, University of Illinois at Urbana-Champaign, March 2001.

Waldorf, B. and Pitfield, D. (2005). The Effects of Demographic Shifts on Non-Automobile Transportation Needs of the Elderly. In: Donaghy, K., Poppelreuter, S. and Rudinger, G. (eds.) Social dimensions of sustainable transport: Transatlantic perspectives. London, Ashgate, pp. 67-89.

Willis, S. J. (2003). Programmatic interventions with the older driver: A conceptual framework. In K. W. Schaie, H-W. Wahl, H. Mollenkopf \& F. Oswald (eds.) Ageing independently: Living ar-rangements and mobility. New York, Springer, pp. 263-301.

World Business Council for Sustainable Development (2001). Mobility 2001. World mobility at the end of the twentieth century and its sustainability. Available at: http://www.wbcsdmobility.org

World Commission on Environment and Development (1987). Our Common Future (the Brundtland Report). Oxford University Press, New York. 